\title{
Colocação pronominal e ensino de português: possibilidades metodológicas para a educação básica
}

\author{
Mirian Santos de Cerqueira* \\ Leosmar Aparecido da Silva** \\ Resumo
}

Este artigo tem como objetivo central apresentar uma possibilidade metodológica de abordagem da colocação pronominal em aulas de língua portuguesa para o ensino básico. Em relação à metodologia, inicialmente, fizemos uma ampla revisão de literatura sobre os clíticos pronominais no português brasileiro; em seguida, selecionamos dois textos literários e uma tira humorística para analisar seus aspectos gramaticais e discursivos, especialmente, os relacionados ao uso dos clíticos, ao mesmo tempo em que problematizamos a transposição didática da análise ao ensino de língua portuguesa. Os resultados mostraram que, nas aulas de língua portuguesa, é possível avançar para além das regras gramaticais prescritivas, valorizar diferentes manifestações de uso da língua e integrar as frentes de língua portuguesa. Estudos como o desenvolvido neste artigo podem contribuir para a reflexão sobre a relação entre gramática, leitura e produção textual.

Palavras-chave: Ensino de português. Português Brasileiro. Colocação pronominal.

\footnotetext{
* Universidade Federal de Goiás (UFG). Doutora em Linguística / Pós-Doutora pela PUC-Rio na área de Psicoloinguística Experimental. Professora e Pesquisadora do Departamento de Linguística e Língua Portuguesa da Faculdade de Letras da Universidade Federal de Goiás. ORCID: https://orcid.org/0000-0001-5409-3503.

** Universidade Federal de Goiás (UFG). Doutor em Estudos Linguísticos com pós-doutorado pela Universidade Federal do Ceará (UFC) na área de descrição e análise linguística. Professor e Pesquisador do Programa de Pós-Graduação em Letras e Linguística da Universidade Federal de Goiás. ORCID: https://orcid.org/0000-0002-3954-3518.
} 


\title{
Pronominal placement and Teaching of Portuguese: methodological possibilities for basic education
}

\begin{abstract}
This paper has as main objective to present a methodological possibility of approach of the pronominal placement in Portuguese language classes for basic education. Concerning to the methodology, first, we did an overview of framework about pronominal clitics in Brazilian Portuguese; after, we selected two literature texts and a humor one to analyze its grammatical and discoursive aspects, specially, those aspects related to the use of clitics. At the same time, we did questions about the didactic transposition of the analysis to the teaching of Portuguese Language. The results showed that, into the Portuguese language classes, it is possible to advance besides prescriptive grammatical rules. It is possible also to value different manifestations of language use and to integrate the basis of Portuguese language. Studies as such as the one developed in this paper can contribute to the reflection about the relationship among grammar, reading and text production.

Keywords: Teaching of Portuguese. Brazilian Portuguese. Pronominal placement.
\end{abstract}

Recebido em: 07/08/2020 // Aceito em: 24/02/2021. 


\section{Introdução}

Muitos estudos linguísticos, tanto na perspectiva funcionalista quanto na perspectiva formalista, têm tratado de descrever e analisar o comportamento dos clíticos pronominais em português, ora centrando-se em aspectos morfossintáticos, ora em aspectos prosódicos, fonético-fonológicos e em suas interfaces. Tais estudos vão desde uma perspectiva sincrônica (GALVES, 2001; NEVES, 2018) até uma perspectiva diacrônica (PAGOTTO, 1993; MARTINS, 1994). Estes últimos o fazem, descrevendo fatos linguísticos que remontam à história do português, de modo a trazer luz para o estado atual das variedades brasileira e europeia; e aqueles tratam do tema considerando a variação intralinguística, ou seja, a gramática do Português Brasileiro (PB) contemporâneo (VIEIRA, 2008; BARROS, 2011). No entanto, o que se observa, apesar de haver estudos que propõem contribuições para o ensino e propostas metodológicas específicas para a colocação pronominal (VIEIRA, 2008), é que, muitas vezes, os resultados de tais pesquisas, por inúmeras razões, parecem não chegar à sala de aula da educação básica de maneira efetiva. Considerando, pois, tais fatos, e acreditando numa articulação necessária entre descrição linguística e o ensino de português, foi que surgiu o nosso interesse em propor uma abordagem metodológica acerca da colocação pronominal em sala de aula de português da educação básica, de modo a considerar os usos linguísticos do PB manifestados em textos, o conhecimento que o aluno já traz consigo no processo de aquisição da língua (gramática internalizada) e os conhecimentos com os quais ele irá operar nas práticas de linguagem, tanto na dimensão epilinguística quanto na dimensão metalinguística. (GERALDI, 1997; BRASIL, 1998; PILATI, 2017). 

possibilidades metodológicas para a educação básica

Para realizar nossa proposta, o presente artigo está organizado do seguinte modo: na primeira seção, fazemos um levantamento sobre alguns estudos, em diferentes perspectivas teóricas, acerca do funcionamento dos clíticos pronominais no português, considerando abordagens normativo-prescritivas, variacionistas, funcionalistas e formalistas. Apontamos algumas diferenças entre o PB e o Português Europeu (PE) acerca de alguns aspectos morfossintáticos, com foco nos clíticos pronominais, relacionando, sempre que possível, tais questões ao ensino de português. Na segunda seção, apresentamos os aspectos metodológicos do estudo. Na terceira seção, analisamos três textos que constituem possibilidades metodológicas para o ensino de português em sua variedade brasileira, centrandonos, especificamente, no uso da colocação pronominal e sua relação com a funcionalidade dos textos e consequentes efeitos de sentidos.

\section{Algumas considerações sobre a colocação pronominal no português e sua relação com o ensino}

Antes de iniciarmos a discussão sobre os usos de clíticos pronominais, em geral, e da colocação pronominal, em específico, e uma possível proposta metodológica para o ensino de português na educação básica, precisamos deixar claro duas questões fundamentais: 1) as perspectivas teóricas que fundamentam nossa proposta; e 2) o que estamos entendendo como clítico, uma vez que há, na literatura linguística, diferentes interpretações e abordagens teóricas sobre o tema, razão pela qual tal categoria pode ser descrita e analisada sob diferentes domínios da gramática e suas interfaces, desde uma perspectiva sincrônica até uma perspectiva diacrônica e também pancrônica. 
Com relação à primeira questão, vamos considerar que, por sua natureza diversificada e complexa, o ensino de português na educação básica não deveria ser pensado apenas sob a perspectiva de uma teoria única, como se essa fosse capaz de dar conta da multiplicidade dos fenômenos linguísticos nesse contexto. Por essa razão, não nos deteremos, neste artigo, em adotar um paradigma específico, quer seja funcionalista, quer seja gerativista. Ao invés disso, lançaremos mão de hipóteses que sejam capazes de nos explicar com maior propriedade o funcionamento do nosso objeto de estudo: colocação pronominal e sua relação com o ensino de português.

No que se refere à segunda questão, podemos dizer que, no âmbito da gramática normativa, clíticos pronominais são conhecidos como "pronomes pessoais do caso oblíquo", ou seja, pertencem à categoria de pronomes que desempenham as funções sintáticas de complementos dos verbos, podendo ser objetos diretos ou objetos indiretos. Tais pronomes podem ser átonos (sem preposição) ou tônicos (com preposição). ${ }^{1}$ Como representantes do primeiro grupo temos: me, te, lhe, $\mathrm{o}$, a e se (correspondentes às $1^{\mathrm{a}}, 2^{\mathrm{a}}$ e $3^{\mathrm{a}}$ pessoas do singular respectivamente) e nos, vos, lhes, os, as e se (correspondentes às $1^{\mathrm{a}}, 2^{\mathrm{a}}$ e $3^{\mathrm{a}}$ pessoas plural, respectivamente). Como representantes do segundo grupo temos: mim, ti, ele, ela e si (equivalentes às $1^{\mathrm{a}}, 2^{\mathrm{a}}$ e $3^{\mathrm{a}}$ pessoas do singular, respectivamente) e nós, vós, eles, elas e si (equivalentes às $1^{\mathrm{a}}, 2^{\mathrm{a}}$ e $3^{\mathrm{a}}$ pessoas do plural, respectivamente), conforme Bechara (2001, p. 64).

De acordo com Bechara (2001, p. 64), os pronomes oblíquos também se classificam como reflexivos ( $1 \mathrm{a}, \mathrm{b}$ e c) e recíprocos ( 2 a e b), conforme se verificam nos exemplos seguintes:

\footnotetext{
1 Ainda acerca de pronomes oblíquos tônicos, Bechara (2001, p. 165) destaca: "se a preposição é com, dizemos comigo, contigo, consigo, conosco, convosco, e não: com mi, com ti, com si, com nós, com vós. Empregam-se, entretanto, com nós e com vós, ao lado de conosco e convosco, quando estes pronomes tônicos vêm seguidos ou precedidos de mesmos, próprios, todos, outros, ambos, numeral ou oração adjetiva, a fim de evidenciar o antecedente.”
} 
(1) a. Eu me vesti rapidamente.

b. Nós nos vestimos.

c. Eles se vestiram.

(2) a. Nós nos cumprimentamos (um ao outro).

b. Eles se abraçaram (um ao outro).

A designação "caso", antecedendo o nome oblíquo, faz referência ao latim, uma vez que, nessa língua, as funções sintáticas são marcadas morfologicamente, ou seja, recebem uma marca de caso morfológico para designar se são nominativos (caso atribuído ao sujeito), acusativos (caso atribuído ao objeto direto), dativos (caso atribuído ao objeto indireto), dentre outros.

No âmbito dos estudos linguísticos, pesquisadores de diferentes abordagens teóricas têm questionado se os clíticos pronominais podem ser considerados como afixos, vocábulos ou outra categoria independente morfossintaticamente. (GALVES, 2001; MARCILESE, 2007; SOARES; RIBEIRO, 2011; BIAZOLLI, 2016, dentre outros).

$\mathrm{Na}$ linha da gramática gerativa, Marcilese (2007) destaca a contribuição de Uriagereka (1995), uma vez que tal autor considera serem os clíticos pronominais unidades morfofonológicas cujas propriedades fazem distinção de afixos e de palavras possuidoras de conteúdo. Segundo Marcilese,

o autor chama a atenção para as semelhanças de natureza sintático/semântica entre os clíticos acusativos de $3^{\mathrm{a}}$ pessoa e os D. ${ }^{2}$ Ambos seriam elementos referenciais e específicos, duas características que, segundo Uriagereka, desempenham um papel decisivo na colocação dos clíticos. Os clíticos atuariam como uma "âncora" para a nova informação, isto é, remeteriam a algo já familiar no discurso. (MARCILESE, 2007, p. 66).

$\overline{2}$ D significa Determinante nos estudos de sintaxe gerativa. 
Numa perspectiva distinta, adotando os pressupostos teórico-metodológicos da sociolinguística variacionista e focalizando os clíticos pronominais no âmbito do português mais especificamente, Vieira (2002), citada por Biazolli (2016), argumenta em torno das seguintes propriedades constitutivas dos clíticos:

[...] há duas características do pronome átono do português que impedem o seu tratamento como afixo, no sentido estrito da palavra: (i) eles não se ligam a raízes vocabulares, mas a uma instância sintática; e (ii) por não constituírem, efetivamente, 'formas presas', têm mobilidade relativa no enunciado, podendo antepor-se ou pospor-se ao verbo. (VIEIRA, 2002, p. 386 apud BIAZOLLI, 2016, p. 36).

Aautora salienta, ainda, que a caracterização sociolinguística com relação ao posicionamento (ordem) de tais elementos tem sido utilizada como uma espécie de indicador para apontar divergências entre o $\mathrm{PB}$ e o $\mathrm{PE}$, conforme atestam inúmeros estudos. (VIEIRA, 2008; ILARI; BASSO, 2014; BASSO, 2019).

No âmbito do ensino da colocação pronominal, Vieira (2008) apresenta três orientações gerais que podem ser adotadas em sala de aula: 1) tradicional-normativa; 2) "progressista"; 3) "sociolinguística inovadora". A primeira dá ênfase aos contextos gramaticais atratores da ênclise, com foco na modalidade escrita. A segunda prevê o uso da próclise como um elemento genuíno do PB, independentemente da modalidade. A terceira considera um trabalho pedagógico que oriente "a opção do aluno na concretização da norma de uso do $\mathrm{PB}$, que prevê a próclise como opção preferencial (sem desconsiderar a realização da ênclise, principalmente com os pronomes o, a(s) e se indeterminador/ apassivador)". (VIEIRA, 2008, p. 143). 

possibilidades metodológicas para a educação básica

Além disso, argumenta a autora, tratar da questão de colocação pronominal no âmbito do ensino de português requer que se considerem múltiplos aspectos, nos mais diferentes níveis da gramática e suas interrelações. Para ilustrar isso, apresentamos a seguir um organograma proposto por Vieira (2008, p. 142) acerca de como podem ser abordados os clíticos pronominais tanto no âmbito da pesquisa descritiva quanto no âmbito do ensino:

Figura 1 - Organograma sobre os clíticos pronominais

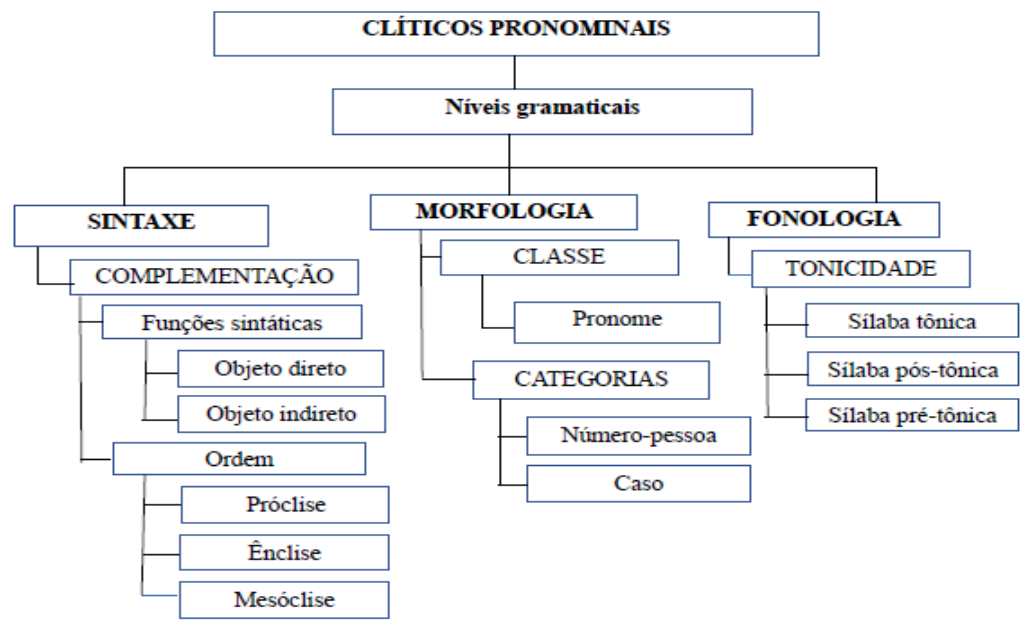

Fonte: Vieira (2008, p. 142).

O quadro apresentado por Vieira (2008) ilustra, de maneira muito didática, algumas das possibilidades de abordagem de estudo para os clíticos pronominais, demonstrando de que maneira cada um dos níveis gramaticais (sintaxe, morfologia e fonologia) pode contemplar o estudo de tais elementos. Isso proporciona, sobretudo ao professor de português da educação básica, ter uma espécie de "mapa cartográfico" de como organizar 
os conteúdos específicos sobre o tema em questão, fornecendo, inclusive, pistas de como podem ser feitos trabalhos (atividades) nas interfaces dos níveis gramaticais apresentados, contribuindo, de alguma maneira, para que sejam questionados exercícios isolados de atividades metalinguísticas realizados em torno desse conteúdo, uma vez que considera a articulação entre diferentes níveis da gramática. Tal fato, por sua vez, pode contribuir de maneira significativa para uma abordagem mais integrada de conteúdos gramaticais, considerando sua funcionalidade e uso em situações sociocomunicativas relevantes. No ensino, essa integração pode se dar tanto em relação aos níveis de análise linguística (sintaxe, morfologia e fonologia) quanto em relação às frentes da língua portuguesa (literatura, gramática, produção de textos).

É importante considerar que propostas como as de Vieira (2008) e outros autores, como Pilati (2017) e Ilari e Basso (2014), por exemplo, nos levam a pensar também na relação entre concepções de aquisição e aprendizagem de línguas, como bem observou Kato (2004), ao postular a hipótese de que a criança brasileira, ao chegar à escola, se depara com uma língua que não corresponde ao seu vernáculo, ou seja, não há uma correspondência direta entre o conhecimento linguístico da criança e os conhecimentos apresentados pelo letramento escolar. Estes últimos, Kato (2004) denomina "gramática do letrado". Para a autora:

[...] no Brasil, ao contrário do que ocorre em Portugal, a gramática da fala e a 'gramática' da escrita apresentam uma distância de tal ordem que a aquisição desta pela criança pode ter a natureza da aprendizagem de uma segunda língua. A situação é ainda mais problemática porque não há estudos comparativos entre o conhecimento linguístico que a criança traz para a 

possibilidades metodológicas para a educação básica

escola e o conhecimento dos letrados contemporâneos, comparação essa que poderia auxiliar a escola em sua tarefa de letramento. (KATO, 2004, p. 1).

Seguindo a hipótese formulada por Kato, diversos pesquisadores têm demonstrado, em suas investigações, que a variedade do português que é objeto de estudo nas escolas brasileiras, de modo geral, é interpretada pelo aluno brasileiro como língua estrangeira ou segunda língua. (MAGALHÃES, 2000; GALVES, 2001; AVELAR, 2017). No âmbito da aquisição do clítico "se", por exemplo, Kato (2017) argumenta que o uso desse clítico tem perdido espaço na gramática dos falantes brasileiros, contrariamente ao que acontece na variedade europeia do português. Isso é atestado também por Barros (2011), ao investigar o (des)uso do reflexivo no português contemporâneo falado em Goiás, em dados como "ele ajoelhou, ele casou".

No PB, de um modo geral, o uso do clítico "se" está reservado, na maioria dos casos, à modalidade escrita, em gêneros textuais/discursivos com maior grau de formalidade e monitoramento, como em "vende-se casa".

Dentro da mesma perspectiva teórica de investigação adotada por Kato (2017), Galves (2001) apresenta um conjunto de dados comparativos das diferenças no uso do clítico "se" nas gramáticas do $\mathrm{PB}$ e do $\mathrm{PE}$, conforme se verifica nos exemplos que seguem sintetizados no quadro abaixo: 


\section{Quadro 1 - Quadro comparativo sobre o uso dos clíticos,}

conforme Galves (2001)

\begin{tabular}{|l|l|l|}
\hline \multicolumn{1}{|c|}{ Tipos } & \multicolumn{1}{|c|}{ Português brasileiro } & \multicolumn{1}{c|}{ Português europeu } \\
\hline Indeterminado & $\begin{array}{l}\text { Nos nossos dias, não usa } \\
\text { mais saia }\left(\text { NURC }^{1}\right) .\end{array}$ & Não se usa mais saia. \\
\hline Médio & $\begin{array}{l}\text { Esta camisa lava } \\
\text { facilmente. }\end{array}$ & $\begin{array}{l}\text { Esta camisa lava-se } \\
\text { facilmente. }\end{array}$ \\
\hline Pronominal & $\begin{array}{l}\text { Joana não matriculou } \\
\text { ainda. }{ }^{2}\end{array}$ & $\begin{array}{l}\text { Joana não se matriculou } \\
\text { ainda. }\end{array}$ \\
\hline Reflexivo & $\begin{array}{l}\text { Maria fez a lista dos } \\
\text { convidados, mas esqueceu } \\
\text { de incluir ela. }\end{array}$ & $\begin{array}{l}\text { Maria fez a lista dos dados, mas } \\
\text { conqueceu de se incluir. }\end{array}$ \\
\hline $\begin{array}{l}\text { Indeterminação } \\
\text { nas infinitivas }\end{array}$ & $\begin{array}{l}\text { É impossivel se achar } \\
\text { lugar aqui. }\end{array}$ & $\begin{array}{l}\text { É impossivel achar lugar } \\
\text { aqui. }\end{array}$ \\
\hline $\begin{array}{l}\text { Estruturas } \\
\text { "difíceis" }\end{array}$ & $\begin{array}{l}\text { O João é difícil de se } \\
\text { convencer. }\end{array}$ & $\begin{array}{l}\text { O João é difícil de } \\
\text { convencer. }\end{array}$ \\
\hline
\end{tabular}

Fonte: Adaptado de Galves (2001, p. 46).

Ainda sobre algumas diferenças no campo de clíticos pronominais entre as gramáticas do PB e do PE, Nunes (2007) apresenta algumas expressões ditas "congeladas" no PB, as quais denominou de "mineirismos", enfocando, mais especificamente, dados do dialeto falado numa cidade do interior de Minas Gerais (Conceição das Alagoas), em seu capítulo intitulado "Triangulismos e a sintaxe do Português Brasileiro", conforme exemplos apresentados em 3 (a-c):

(3) a. bem-te-vi.

b. Acabou-se o que era doce.

c. Abre-te Sésamo.

O posicionamento do clítico pronominal "te" (de $2^{\mathrm{a}}$ pessoa do singular), no exemplo, em 3 (a), deve-se ao fato de que, 
no $\mathrm{PB}$, em decorrência de um processo de reanálise, "bem-tevi" é interpretado como um item do léxico, diferentemente do que ocorre em PE, em que "bem", no contexto em questão, é interpretado como marcador de ênfase. Tanto uma quanto outra análise estão alinhadas às hipóteses de que a próclise é generalizada em PB (conforme também atestam GALVES, 2001; KATO, 2004; ILARI; BASSO, 2014; BASSO, 2019), ao passo que o PE permite tanto próclise quanto ênclise.

Com relação ao exemplo em 3 (b), o que temos, segundo Nunes (2007), é uma ênclise decorrente do fator prosódico, ou seja, a rima ocasionada pela redução do ditongo na forma verbal [acabô-se] com [doce].

No que se refere ao exemplo em 3 (c), o autor argumenta que devem ser considerados dois fatores: (i) o fato de que, no dialeto mineiro, a perda de clíticos reflexivos é visível, razão pela qual o clítico "te" não seria analisado como um clítico típico e, consequentemente, não haveria ênclise nesse contexto; (ii) o fato de não haver ênclise possibilita que esse elemento seja aglutinado, por um processo de reanálise, à palavra seguinte, passando a figurar como "Tisésamo", formando, assim, o enunciado "Abre, Tisésamo". Por serem proparoxítonas, "Sésamo e Tisésamo" poderiam se passar por "palavras mágicas", já que esse padrão de acento não é comum em português.

Nunes (2007) argumenta que as aparentes idiossincrasias presentes nas expressões apresentadas são, na verdade, decorrentes das propriedades marcantes do PB, dentre elas, o sistema proclítico de colocação pronominal.

Ainda nessa direção, ou seja, reconhecendo a hipótese do conhecimento intuitivo do falante sobre sua língua e distinguindo-o do conhecimento sobre uma dada regra imposta 
pela gramática normativa, Avelar (2017) apresenta uma discussão em torno da função sintática que seria atribuída ao clítico "se" na gramática do português falado no Brasil. $\mathrm{O}$ autor exemplifica tal questão com um uso "intrigante" do clítico "se", conforme podemos verificar na sentença abaixo:

(4) Vende frango-se.

Embora considerado agramatical, o exemplo acima foi descrito em uma crônica de Martha Medeiros, ${ }^{3}$ em que a autora reporta o uso do clítico em um cartaz encontrado numa comunidade da cidade do Rio de Janeiro. O caso em questão é ilustrativo de uma situação de hipercorreção, em que o usuário da língua, parecendo saber inconscientemente da pressão sociolinguística em torno da escrita, tenta passar credibilidade aos seus interlocutores, utilizando uma forma considerada de prestígio.

Avelar (2017) argumenta que, apesar de parecer incomum e até mesmo agramatical, o uso do clítico "se", no contexto mencionado, já era apresentado há cerca de 120 anos, segundo os estudos de Said Ali, ou seja, esse pronome não seria considerado como partícula apassivadora, mas como índice de indeterminação de sujeito. (AVELAR, 2017, p. 119).

Esse uso do clítico "se" (uma tentativa de empregar uma ênclise) ilustra, de certo modo, o que vem acontecendo no PB: a perda do "se" em contextos de oralidade. O dado parece confirmar, de alguma maneira, a hipótese defendida por Kato acerca da "gramática do letrado", ou seja, tal clítico não faz parte da gramática internalizada do falante em questão, sendo,

3 Cf. MEDEIROS, Martha. Vende frango-se. Zero hora, Porto Alegre, 9 nov. 2005. 
provavelmente, tema de contexto exclusivamente escolar, decorrente de uma explicitação metalinguística em situação de letramento.

Isso está alinhado ao que Tarallo (1996, p. 70) propôs, quando tratou da emergência de uma gramática brasileira. Segundo o autor, “[...] o perfil da nossa gramática brasileira (no sentido de gramática normativa) tem sido ditado pela tradição portuguesa e só esse fato torna o vácuo entre língua oral e escrita muito mais profundo no Brasil do que em Portugal."

Por todas as razões aqui apresentadas, defendemos que toda proposta de ensino que se queira capaz de contemplar a realidade linguística de seus falantes deve considerar o conhecimento intuitivo que este traz sobre sua língua (PILATI, 2017), para que possa, inclusive, ser inserido em práticas de letramento exigidas pela sociedade contemporânea. Conforme argumenta Pilati (2017, p. 15), "[...] é necessário criar alternativas às formas tradicionais de levar a língua portuguesa às escolas brasileiras".

\section{Metodologia}

Levando em consideração as discussões teóricas apresentadas na seção anterior deste artigo, partiremos da hipótese de que os usos públicos da língua e o conhecimento dos falantes sobre a língua devem ser ferramenta indispensável para elaborar uma proposta metodológica de ensino de língua portuguesa para a educação básica. Segundo Pilati (2017), o conhecimento linguístico do aluno desempenha papel fundamental quando se pensa em alternativa para o ensino, razão pela qual as atividades didáticas devem ter como ponto de partida o uso linguístico, que reflete a criatividade dos usuários da língua como sujeitos capazes de conhecê-la, refletir sobre ela e interagir no mundo. 
Sobre a caracterização deste trabalho, importante esclarecer que, quanto à natureza, é um estudo aplicado, uma vez que procura transpor resultados de estudos teórico-descritivos ao ensino de língua portuguesa na educação básica. Quanto à abordagem, constitui-se como um trabalho qualitativo, visto que se pauta pela observação de múltiplas realidades e de suas contribuições para um campo específico.

Em relação aos passos do estudo, em um primeiro momento, fizemos uma ampla revisão de literatura, verificando a contribuição de diferentes perspectivas teóricas não só para a abordagem da colocação pronominal no PB contemporâneo, como também a sua relação com o ensino de língua materna.

Em um segundo momento, com base em nossa prática como ex-professores do ensino básico e também com base na prática de nossos alunos de estágio no curso de Licenciatura em Letras: Português, selecionamos três textos — dois literários e uma tira humorística - para realizamos uma análise dos aspectos sintático-discursivos presentes nos textos analisados, principalmente, os relacionados ao uso da colocação pronominal.

Nos textos, analisamos de que modo os pronomes clíticos se comportam e de que maneira tal comportamento pode ser tratado em sala de aula de português na educação básica, verificando não só o funcionamento do pronome em si, mas todo o conjunto do texto em seu potencial de significação, considerando-se, desse modo, aspectos morfossintáticos, semânticos e textuaisdiscursivos no funcionamento da língua para a produção de sentidos. 

possibilidades metodológicas para a educação básica

\title{
3 Análise e discussão dos dados: uma proposta de ensino sobre colocação pronominal
}

Nesta seção, são apresentadas algumas possibilidades de trabalho sobre a posição dos clíticos pronominais no PB, considerando-se aspectos sintático-discursivos.

De acordo com alguns estudos sobre análise linguística (GERALDI, 1997; NEVES, 2004; PILATI, 2017) e com os documentos oficiais (BRASIL, 1998; BRASIL, 2018), o ensino de gramática deve ser ativo e reflexivo, de modo a contribuir para o desenvolvimento da leitura e da escrita em situações relevantes socialmente. Recortamos, para este texto, as contribuições acerca dos usos dos clíticos pronominais para a produção de leitura crítica, de forma a ajudar o aluno a perceber seus efeitos de sentido.

O primeiro texto selecionado para este trabalho é a música "História de uma gata", de Chico Buarque (1977), que integra as canções do disco Os saltimbancos e que a reproduzimos a seguir:

\author{
Me alimentaram \\ Me acariciaram \\ Me aliciaram \\ Me acostumaram \\ O meu mundo era o apartamento \\ Detefon almofada e trato \\ Todo dia filé-mignon \\ Ou mesmo um bom filé de gato \\ Me diziam todo momento \\ Fique em casa não tome vento \\ Mas é duro ficar na sua \\ Quando à luz da lua \\ Tantos gatos pela rua \\ Toda a noite vão cantando assim \\ Nós gatos já nascemos pobres
}


Porém já nascemos livres

Senhor senhora ou senhorio

Felino não reconhecerás

De manhã eu voltei pra casa

Fui barrada na portaria

Sem filé e sem almofada

Por causa da cantoria

Mas agora o meu dia-a-dia

É no meio da gataria

Pela rua virando lata

Eu sou mais eu mais gata

Numa louca serenata

Que de noite sai cantando assim

Nós gatos já nascemos pobres

Porém já nascemos livres

Senhor senhora ou senhorio

Felino não reconhecerás

Fonte: Holanda (1977).

Os saltimbancos foi produzido por Chico Buarque em 1997. Conforme esclarecem Mendes e Alexandre (2018), foi inspirado em um disco infantil italiano intitulado I Musicanti, de composição de Luis Enríquez Bacalov e de Sergio Bardotti. Importante esclarecer também que o conjunto das canções do disco estabelece relação intertextual com a história infantil Os músicos de Bremen, dos Irmãos Grimm, ${ }^{4}$ e que, conforme considerações de Heloísa Buarque, conhecida como Miúcha (2017), em entrevista à Revista Crescer, Os saltimbancos ficou gravado na memória das pessoas, porque aborda questões importantes da sociedade atual, tais como exploração, união, justiça, solidariedade e liberdade. Há relação interdiscursiva com o discurso político e com o discurso literário. $\mathrm{Na}$ dimensão política, os animais representam servos, e os proprietários,

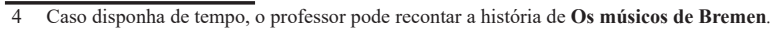


os senhores feudais. (MENDES; ALEXANDRE, 2018). Na dimensão literária, a canção assemelha-se, na forma e no conteúdo, a um poema com ritmo, cadência e lirismo.

Em um movimento interativo com os alunos, o professor pode ir construindo uma interpretação geral do texto. O tema da liberdade feminina, nesse sentido, parece ser expressivo, uma vez que a gata (a mulher) é inicialmente cooptada pelo seu dono, que lhe oferece bom trato, Detefon, filé mignon em troca de sua submissão (fique em casa). A sua identidade como gata, no entanto, a convida a sair para a rua e formar parceria com os outros gatos que, juntos, cantam a satisfação em serem plenamente livres.

Em relação aos clíticos pronominais, chama a atenção no texto o uso da próclise em início de sentença em "me alimentaram / me acariciaram / me aliciaram / me acostumaram". Há aí uma atitude subversiva no sentido de que, normalmente, o texto literário é usado como referência pelas gramáticas tradicionais como a representação do vernáculo, e, neste texto literário especificamente, rompeu-se com a regra gramatical que diz que "ocorre ênclise quando a oração é iniciada com o verbo" (BECHARA, 2001, p. 588), ou seja, não se recomenda o emprego de pronome oblíquo átono em início de sentença, antes do verbo. $\mathrm{O}$ uso, contudo, consagra como legítimas construções como "te amo, se liga, te aprume, se ajeite", etc., de tal modo que é impossível que, mesmo em uma perspectiva prescritiva, duzentos milhões de brasileiros estejam "errados", e o vernáculo do português europeu, "correto". Daí, confirma-se o conceito de "gramática do letrado", proposto por Kato (2004), ao distinguir aquilo que é fruto da educação escolar e aquilo que é fruto de conhecimento linguístico do falante. 
Em termos de trabalho com a leitura/interpretação, nos quatro primeiros versos, em que a gata relata o seu processo de cooptação, observa-se a presença do clítico "me", seguido de verbos que se iniciam com a vogal/a/ (alimentaram, acariciaram, aliciaram, acostumaram). Essa combinação sintática cria o efeito da imitação do miado da gata ([miaw]limentaram, [miaw]cariciaram, [miaw]liciaram, [miaw]costumaram). $\mathrm{Na}$ interpretação da canção por Nara Leão, verifica-se a reprodução do miado da gata, ao alongar-se o /a/ inicial dos verbos, em "aaalimentaram", "aaacariciaram", "aaaliciaram", "aaacostumaram", conforme afirmação de Mendes e Alexandre (2018, p. 20).

$\mathrm{O}$ efeito aqui analisado faz interface entre dois níveis gramaticais: o fonético/fonológico e o sintático, que, por sua vez, fazem interface com um texto literário. $\mathrm{O}$ trabalho com tal texto e com tal efeito discursivo em sala de aula, associado com uma reflexão sobre o uso da próclise como uma marca linguísticoidentitária do $\mathrm{PB}$, tem a vantagem de mediar os alunos no processo de sua formação como leitores, no geral, e de leitores literários, no específico. Uma outra vantagem é a apresentação de uma gramática que emerge dos textos (NEVES, 2018), uma gramática com a qual é possível criar, fazer associações, brincar. Uma gramática que lhes faça sentido, que é "da gente" (ILARI; BASSO, 2014), que está próxima das nossas experiências linguístico-sociais cotidianas, que constitui conhecimento já internalizado.

No momento de suas produções textuais, o aluno poderá recriar o mesmo efeito de sentido com outras palavras e em outros contextos, porque teve a experiência, no momento da leitura, de perceber o modo como o enunciador selecionou 
determinados sons, associou-os a determinadas palavras em posições estratégicas na sentença. Estaria criada, assim, a tríade unificada em que se trabalham, por meio de um único texto, de um gênero específico, as frentes "literatura, análise linguística e produção textual" (GERALDI, 1997; VIEIRA, 2008), que, muitas vezes, são abordadas de modo desmembrado, como se a literatura não se comunicasse com a gramática, e ambas não se comunicassem com a produção textual.

Para além da análise do tema do texto, que pode ser interpretado também como a liberdade feminina (a gata sai de casa para viver com os seus amigos gatos), no estudo da colocação pronominal, o professor pode contrapor construções oracionais efetivamente usadas no texto com outras parafraseadas do texto, mudando a colocação dos pronomes, como se verifica a seguir:

(4) me alimentaram / me acariciaram / me aliciaram / me acostumaram / me diziam todo momento

(4') alimentaram-me / acariciaram-me / aliciaram-me / acostumaram-me / diziam-me todo momento

A partir dessa contraposição e com base nas orientações gerais apresentadas por Vieira (2008) acerca da colocação pronominal em sala de aula, o professor pode refletir com os alunos sobre os seguintes aspectos:

i) a estranheza ou não das construções em (4');

ii) a consonância ou não dessas construções com a variedade do português falado no Brasil;

iii) a perda ou não do efeito sonoro que reproduz literalmente o miado da gata; 
iv) o grau de formalidade de (4) e de (4') na "fala" de uma gata popular;

v) a função sintática do pronome oblíquo, que, neste caso, desempenha a função de objeto direto dos verbos presentes nas construções e que, no nível textual, faz referência à gata;

vi) a indeterminação do sujeito alcançada por meio do uso do plural dos verbos em questão.

O professor pode, ainda, refletir com os alunos sobre a produtividade ou não na modalidade falada entre, por exemplo, "me alimentaram" e "não reconhecerás" (último verso). Na última construção, a forma verbal "reconhecerás" ocorre na segunda pessoa do singular, típica de uma variedade escrita formal no $\mathrm{PB}$, o que parece causar estranheza, em um primeiro momento, se comparado com o uso da próclise em "me alimentaram".

Um outro texto que pode servir para a produção de leitura, análise linguística e produção textual é o poema "Sequências", de Cora Coralina, em que o eu enunciador narra um episódio de sua infância:

Sequências

$1 \mathrm{Eu}$ era pequena. A cozinheira Lizarda tinha nos levado ao mercado, minha irmã, eu.

Passava um homem com um abacate na mão e eu inconsciente:

5 "Ome, me dá esse abacate..."

$\mathrm{O}$ homem me entregou a fruta madura.

Minha irmã, de pronto: "vou contar pra mãe que ocê pediu abacate na rua."

Eu voltava trocando as pernas bambas.

10 Meus medos, crescidos, enormes...

A denúncia confirmada, o auto, a comprovação do delito. 
O impulso materno... consequência obscura da

escravidão passada, o ranço dos castigos corporais.

$15 \mathrm{Eu}$, aos gritos, esperneando.

O abacate esmagado, pisado, me sujando toda.

Durante muitos anos minha repugnância por esta fruta trazendo a recordação permanente do castigo cruel.

Sentia, sem definir, a recreação dos que ficaram de fora, 20 assistentes, acusadores.

Nada mais aprazível no tempo, do que presenciar a criança indefesa espernear numa coça de chineladas.

"é pra seu bem," diziam, "doutra vez não pedi fruita na rua."

Fonte: Coralina (2004, p. 92).

O texto é elucidativo de castigos corporais praticados contra crianças no passado. Um enunciador adulto rememora uma "Sequência" episódica da infância, na qual a então criança pede para um homem na rua um abacate e leva-o para casa. Diante da "inconvencionalidade" da atitude, considerada "inconsciente" pelo enunciador, a criança leva uma surra de chineladas da mãe, sob o escárnio de adultos espectadores.

A sentença-enunciado que desencadeia todo o conflito da história é aquela em que a menina pede o abacate ao homem nos seguintes termos: "ome, me dá esse abacate". Dado que o vocativo é um elemento extrassentencial, a sentença-enunciado inicia-se com o clítico acusativo, em posição anterior ao verbo, constituindo um caso de próclise.

A sentença reproduz, em discurso direto, a fala da menina, o que mostra que a próclise em início de sentença é espontânea e ocorre de forma natural na língua falada no PB (KATO, 2004; NUNES, 2007; BASSO, 2019). Esse uso reflete a defesa política de Oswald de Andrade, no início do século XX, de uma língua 
brasileira com características próprias, tal como se observa no poema "Pronominais", transcrito a seguir:

\author{
Dê-me um cigarro \\ Diz a gramática \\ Do professor e do aluno \\ E do mulato sabido \\ Mas o bom negro e o bom branco \\ Da Nação Brasileira \\ Dizem todos os dias \\ Deixa disso camarada \\ Me dá um cigarro
}

Fonte: Andrade (2003, p. 167)

No poema "Pronominais" (ANDRADE, 1972, p. 167), o autor contrapõe a construção "dê-me um cigarro", que reflete a gramática "do professor e do aluno e do mulato sabido", à construção "me dá um cigarro", própria do "bom negro" e do "bom branco da nação brasileira". Tanto no poema de Cora Coralina quanto no poema de Oswald de Andrade, há o uso do clítico acusativo no início da sentença. No poema de Cora Coralina, o uso é proveniente de uma fala natural da menina, uma reprodução do que ocorria na língua comum vilaboense. No poema de Oswald de Andrade, o uso demarca, de modo explícito, uma defesa política, por meio da qual se distingue o português do colonizador e o português do brasileiro. Ambos os poetas são modernistas e, como se sabe, no Modernismo de 1922, defendia-se uma sintaxe mais livre e mais próxima do uso da língua comum brasileira. O compromisso político de Cora se revela em um dado de fala em que a estrutura ocorre, e o compromisso político de Oswald se revela em toda a extensão do texto, ao mostrar que a posição de um pronome implica a diferenciação de dois mundos, de dois pontos de vista, de duas línguas, enfim. 
Toda essa reflexão pode ser levada para a sala de aula, inclusive o estudo comparado dos dois textos poéticos, em que ocorre o mesmo fenômeno sintático, com o acréscimo de que a posição sintática do pronome é reflexo do posicionamento ideológico daqueles que defendem que o PB tem uma identidade.

Para além das reflexões sobre a sentença que desencadeia todo o restante da narrativa, é ainda possível desenvolver com os alunos reflexões orais ou por meio de atividades sobre os seguintes aspectos gramaticais-textuais-discursivos do texto: 1) o pronome "nos" do segundo verso, que está entre V1 (tinha) e V2 (levado), na construção "tinha nos levado", tem função textual catafórica e cria o efeito discursivo de criar leve suspense no texto sobre a quem esse "nos" se refere, além de revelar parte do estilo de Cora; 2) no sexto verso, em "O homem me entregou a fruta madura", novamente ocorre próclise, mas agora na fala da personagem adulta, que, mesmo usando a norma padrão, faz uso da próclise sem palavra atrativa; 3) a enumeração de três sintagmas nominais ("A denúncia confirmada, o auto, a comprovação do delito", $11^{\circ}$ verso) relaciona ironicamente o episódio narrado nas "Sequências" com as fases de um processo jurídico penal, ocorrendo aí uma mescla entre o discurso poético e o discurso jurídico; 4) remissão ao fato histórico da escravidão nos $12^{\circ}$ e $13^{\circ}$ versos ("O impulso materno... consequência obscura da / escravidão passada”), nos quais há um verbo implícito e o adjetivo "obscura" avalia negativamente o impulso materno de surrar a criança sem, necessariamente, culpá-la pelo ato; 5) o momento da surra em si no verso 15 (" $\mathrm{Eu}$, aos gritos, esperneando") não é dito explicitamente, devendo ser inferido; 6) no verso 17 ("Durante muitos anos minha repugnância por esta fruta"), a enunciadora relata, por meio de uma frase 
nominal, uma das consequências da surra: aversão ao abacate; 7) os versos de 19 a 23 constituem-se como versos-denúncia de adultos escarnecedores que, sádicos, observavam a surra da criança; 8) a frase-desfecho, em discurso direto, mostra a ironia de que o que é ruim (a surra) é bom (educativo) no sentido de que, com a surra, se aprenderá a não pedir fruta na rua: “é pra seu bem," diziam, "doutra vez não pedi fruita ${ }^{5}$ na rua."

Apesar de não ser o nosso foco, também, no que se refere à produção textual, diferentes propostas de trabalho podem surgir do texto "Sequências": 1) um artigo de opinião sobre o tema da surra como mecanismo educativo; 2) um relato de experiência pessoal ou de terceiros, em que houve castigo por algum motivo; 3) a produção de um vídeo (no estilo dos youtubers, de que tanto os adolescentes gostam), orientando os pais sobre a educação dos filhos e as consequências de castigos corporais. Além dos aspectos textuais-discursivos pertinentes à avaliação das produções textuais, o professor pode ficar atento ao uso que os alunos fazem dos clíticos pronominais em seus textos. Pode, inclusive, coletar e quantificar dados para sistematizar diferentes padrões de usos e, com isso, (re)direcionar a sua prática. Seria um modo de ter acesso ao conhecimento que o aluno já tem internalizado e aqueles que estão sendo adquiridos no âmbito do letramento escolar.

A análise do texto "Sequências" e as propostas aqui empreendidas mostram a possibilidade de se trabalhar a colocação pronominal, em especial, o uso da próclise como uma norma concreta, sociolinguisticamente inovadora, do PB, tal como defende Vieira (2008). Além disso, a abordagem aqui apresentada pressupõe, como já dito anteriormente, a

5 A forma variante "fruita", provavelmente, causará algum tipo de estranhamento ao aluno. Logo, caberá ao professor explicitar historicamente a diferença sociolinguística entre "fruita" e "fruta". 
integração entre o ensino de literatura/interpretação de textos, análise linguística e produção de textos, já que as três frentes da disciplina língua portuguesa têm a linguagem como elemento comum. Além disso, o texto "Sequências" integra o patrimônio cultural da literatura brasileira, possui uma gramática que emerge de si e apresenta também temáticas atuais, que estão no dia a dia do aluno e que, por isso, podem constituir proposta de produção de texto.

Um texto bastante utilizado em livros didáticos, provas de concurso ou em sites de atividades de língua portuguesa disponíveis na internet é uma tira criada por Laerte e publicada originalmente na Folha de S. Paulo. Respeitando o direito autoral de imagens, reproduziremos, a seguir, somente a situação comunicativa e os diálogos dos personagens:

Um garoto, de óculos, está sentado no sofá lendo um livro, quando chega um adolescente, e eles travam o seguinte diálogo:

- Me diga uma coisa...

- O correto é "diga-me"...

— Tá, me desculpe...

— O correto é "desculpe-me".

- Dane-se!

- Agora acertou.

Fonte: Laerte (2014).

O texto dessa tira é, provavelmente, bastante utilizado para tratar da colocação dos clíticos pronominais justamente porque faz referência crítica às tensões entre usos linguísticos, à gramática da norma e à gramática do uso, à intolerância radical ao que se estabeleceu como "errado".

$\mathrm{Na}$ tira, um dos personagens, utilizando-se de sua competência pragmática de adequar sua fala a uma situação 
de informalidade e, utilizando-se de formas linguísticas características do português brasileiro, diz "me diga uma coisa" e "me desculpe". Nesses dois momentos de sua fala, o clítico "me" antecede as formas verbais "diga" e "desculpe", o que, supostamente, contrariaria a gramática normativa, que considera erro fazer uso da próclise em início de frases. O segundo personagem "corrige" o primeiro, dizendo "o correto é 'digame" e "o correto é "desculpe-me". O segundo personagem, apesar de leitor, deixa de observar com criticidade o critério pragmático de adequar as formas linguísticas à situação da interação. Ao invés disso, mostra-se intolerante em relação às variantes próprias da língua falada e, em consequência disso, o processo comunicativo inviabilizou-se, já que aquilo que o primeiro personagem queria comunicar ("me diga uma coisa...") não foi comunicado. As reticências materializam o conteúdo linguístico daquilo que deveria constituir a comunicação.

Enquanto o primeiro personagem procura ser polido, dizendo "tá, me desculpe", ele é hostilizado pelo segundo personagem, que lhe aponta erros na fala. No último quadrinho, contudo, quando o personagem diz "dane-se", abandonando a polidez, o segundo personagem lhe faz, segundo o seu ponto de vista, um elogio, dizendo "agora acertou". A ironia permeia toda a dinâmica do diálogo. Em "dane-se", porém, há um caso de reanálise (NUNES, 2007), ou seja, o verbo e o clítico fundiramse, formando uma unidade significativa, tal como funcionam as expressões idiomáticas ou as expressões conhecidas como "cristalizadas". Devido ao processo de fusão entre o verbo no imperativo e o argumento interno, segundo Barros (2011, p. 128), "não é possível atribuir uma função específica ao pronome, haja vista que ele integra uma expressão cujos elementos 

possibilidades metodológicas para a educação básica

perderam sua função composicional". O suposto "acerto" do personagem, então, é resultante desse processo de fusão, e não necessariamente do conhecimento da regra da gramática normativa. O personagem vigilante da norma linguística parece, portanto, não ter se atentado para a reanálise sofrida pela expressão "dane-se", já que, ao que parece, a dinamicidade da língua não lhe é interessante, porque contraria sua postura conservadora.

Há, portanto, nesse texto, o ponto de vista de seu produtor (LAERTE) que se manifesta por meio de uma crítica humorística e irônica: a de que o monitoramento linguístico ostensivo e aplicável a qualquer situação, praticado pelos "doutos defensores do vernáculo", constitui um problema, porque, além de estar distante da realidade linguística brasileira, impede que a comunicação se estabeleça com dinamicidade e fluidez.

É um texto relevante para se levar para a sala de aula, já que, com a mediação do professor, ajudará os alunos a fazerem reflexão sobre os usos linguísticos e sobre as tensões sociais provocadas pelas diferenças no uso da língua. Além disso, ajudará os alunos a desenvolverem leitura crítica, interpretação de humor (POSSENTI, 1998; NEVES, 2004) e percepção dos meios linguísticos utilizados para produzir ironia. Todas essas habilidades cognitivas (reflexão, sentidos contrastivos, percepção de ironia), aprendidas no momento da leitura, poderão ser usadas de modo mais ou menos monitorado no momento da produção textual, resultando em uma escrita também mais ou menos autoral. 


\section{Considerações finais}

Pretendemos mostrar, neste artigo, por meio de atividades didáticas, que é possível aliar os achados dos estudos descritivos ao ensino de língua portuguesa, sem desconsiderar a norma padrão da língua e os usos reais e intuitivos que os estudantes trazem em sua gramática internalizada. (PILATI, 2017). Foi possível ver, também, que é importante que se considerem as especificidades dos usos dos clíticos pronominais, levando em conta que muitos usos apregoados pela gramática normativa são decorrentes da língua usada por autores clássicos, sem, na maioria das vezes, acompanhar a evolução do sistema pronominal do português falado no Brasil.

Com relação à posição dos clíticos (não apenas o clítico "se") na sentença, foi possível evidenciar, por meio de dados linguísticos, que o português faladono Brasil também se diferencia grandemente do português falado em Portugal. Neste, as crianças, ainda no processo de aquisição, selecionam, preferencialmente, a posição de ênclise em relação ao verbo. Contrariamente, no Brasil, o que se adquire, de maneira generalizada, nesse processo, é a posição de próclise. Para aprender sobre o funcionamento da ênclise, a criança brasileira precisa da aprendizagem formal, via educação escolar (KATO, 2004; 2017). Esse ensino, por sua vez, geralmente, acontece em contexto tradicional, cujo enfoque são atividades metalinguísticas, desconsiderando-se, na maioria das vezes, os usos linguísticos e/ou epilinguísticos das crianças em processo de aquisição da língua.

O trabalho de análise dos textos "História de uma gata", "Sequências" e da tira de Laerte revelou, dentre outros aspectos, que: a) a gramática se revela nos textos (NEVES, 2018) e 
constitui recurso fundamental para a criação de efeitos de sentido, como, por exemplo, a criação de onomatopeias por meio do clítico pronominal e de verbos com algumas especificidades fonológicas; b) os níveis de análise linguística corroboram conjuntamente para a produção de sentido nos textos; c) as habilidades de leitura, análise linguística e produção textual podem estar integradas, por meio de um plano de ensino que considere a língua em uso, atualizado em textos de diferentes gêneros; d) certos usos linguísticos, tais como o emprego do clítico pronominal em posição proclítica, no início de sentença, além de revelar uma característica identitária do $\mathrm{PB}$, é um fenômeno que motivou (e ainda motiva) defesas ideológicas; e) a consideração da regra gramatical prescritiva por ela mesma pode inviabilizar a fluidez da comunicação; f) a reflexão sobre os usos linguísticos ajuda os estudantes a realizarem leitura crítica; g) no momento da escrita, os alunos podem se utilizar de recursos linguísticos percebidos na leitura e desenvolverem uma escrita autoral.

Por todos os argumentos apresentados, acreditamos que somente contemplando a diversidade de usos linguísticos é que contribuiremos para a construção de um ensino de língua portuguesa mais reflexivo na educação básica, formando, desse modo, leitores e produtores de textos nos mais diferentes gêneros, para atuarem de maneira adequada nas mais variadas situações de uso público da linguagem.

\section{Referências}

ANDRADE, O. de. Pronominais. In: Pau-Brasil. 2 ed. São Paulo: Globo, 2003, p. 167. 
AVELAR, J. O. Saberes gramaticais na escola. São Paulo: Pontes, 2017.

BARROS, D. M. de. Aspectos funcionais relativos ao (des) uso do reflexivo no dialeto goiano. 2011. 2011. Dissertação (Programa de Pós Graduação em Letras e Linguística) Universidade Federal de Goiás, Goiânia, 2011.

BECHARA, E. Moderna gramática portuguesa. 37. ed. rev. e ampl. Rio de Janeiro: Lucerna, 2001.

BASSO, R. M. Descrição do português brasileiro. São Paulo: Parábola, 2019.

BIAZOLLI, C. C. Posição de clíticos pronominais em duas variedades do português: inter-relações de estilo, gênero, modalidade e norma. 2016.381f. Tese (Doutorado em Linguística e Língua Portuguesa) - Unesp, Araraquara, 2016.

BRASIL. Ministério da Educação e Desporto. Parâmetros Curriculares Nacionais: $3^{\circ}$ e $4^{\circ}$ ciclos do ensino fundamental. Brasília: SEF, 1998.

BRASIL. Ministério da Educação (MEC). Base Nacional Comum Curricular: educação é a base. Brasília: MEC, 2018. Disponível em: <http:// basenacionalcomum.mec.gov.br/ images/BNCC_EI_EF_110518_versaofinal_site. pdf $>$. Acesso em: 22 jul. 2020.

CORAlinA, C. Sequências. In: CORALINA, C. Melhores poemas. Seleção de Darcy França Denófrio. São Paulo: Global, 2004. p. 92.

GALVES, C. Ensaios sobre as gramáticas do português. Campinas, SP: Unicamp, 2001.

GERALDI, J. W. Portos de passagem. 4. ed. São Paulo: Martins Fontes, 1997.

HOLANDA, C. B. de. Os saltimbancos. 1977. Disponível em: $<$ https://www.letras.mus.br/os-saltimbancos/173787/>. Acesso. 30 jun. 2020. 

possibilidades metodológicas para a educação básica

ILARI, R. A linguística e o ensino da língua portuguesa. São Paulo: Martins Fontes, 1992.

ILARI, R.; BASSO, R. O português da gente: a língua que estudamos, a língua que falamos. São Paulo: Contexto, 2014.

KATO, M. A. A gramática do letrado. Unicamp. Ms., 2004.

KATO, M. A. A gramática do letrado: questões para a teoria gramatical. In: MARQUES, M. A. et al. (org.). Ciências da linguagem: 30 anos de investigação e ensino. Braga: Centro de Estudos Humanísticos (Universidade do Minho), 2005. p. 131145.

KATO, M. A. A variação no domínio dos clíticos no Português Brasileiro. Linguística 33, [s. l.], v. 1, p. 135-152, jun. 2017.

LAERTE. Me diga uma coisa. Folha de S. Paulo. 2014. Disponível em: $<$ https://wordsofleisure.com/2014/03/02/tirinhado-dia-me-diga-uma-coisa/>. Acesso: 3 ago. 2020.

MAGALHÃES, T.M.V. Aprendendo o sujeito nulo na escola. 2000. 90f. Dissertação de Mestrado. Unicamp: Campinas, SP, 2000.

MARCILESE, M. Aquisição de complementos pronominais acusativos: um estudo experimental contrastivo entre 0 Português Brasileiro e o Espanhol Rio-Platense. 2007. $155 f$. Dissertação (Mestrado em Letras) - PUC-Rio, Rio de Janeiro, 2007.

MARTINS, A. M. Clíticos na história do português. 1994. 628f. Tese (Doutorado em Linguística). Faculdade de Letras, Universidade de Lisboa, Lisboa, 1994.

MENDES, M. das D. N.; ALEXANDRE, A. B. A intervocalidade mostrada em canções para crianças. Discursividades, [s. l.], v. 2, n. 1, p. 7-27, mar. 2018.

MIÚCHA. A obra marcou gerações porque falava de questões que estão inseridas na sociedade: exploração, liberdade, união, 
justiça... Revista Crescer, 22 mar. 2017. Entrevista concedida a Renata Menezes. Disponível em: <https://revistacrescer.globo. com/Saltimbancos-40-anos/noticia/2017/03/obra-marcougeracoes-porque-falava-de-questoes-que-estao-inseridas-nasociedade-exploracao-liberdade->. Acesso em: 30 jun. 2020.

NEVES, M. H. de M. Que gramática estudar na escola? Norma e uso na língua portuguesa. São Paulo: Contexto, 2004.

NEVES, M. H. de M. A gramática do português revelada em textos. São Paulo, SP: Editora Unesp, 2018.

NUNES, J. Triangulismos e a sintaxe do português brasileiro. In: CASTILHO, A. de et al. (Org.). Descrição, aquisição e história do português brasileiro. Campinas, SP: Pontes/FAPESP, 2007. p. 25-33.

OLIVEIRA, M. de. Ensino de língua portuguesa: os clíticos acusativos. s/d. Disponível em: <edisciplinas.usp.br>. Acesso em: 30 jun. 2020.

PAGOTTO, E. Clíticos, mudança e seleção natural. In: ROBERTS, I.; KATO, M. A. (org.). Português brasileiro: uma viagem diacrônica. Campinas: Editora da Unicamp, 1993. p. 185-206.

PILATI, E. Linguística, gramática e aprendizagem ativa. Campinas, SP: Pontes Editores, 2017.

POSSENTI, S. Os humores da língua: análises linguísticas de piadas. Campinas: Mercado de Letras, 1998.

SALLES, H. M. M. L. Ensino de Língua Portuguesa: aspectos teóricos e metodológicos do ensino de gramática. Uma entrevista com a Professora Heloísa Maria Moreira Lima Salles (Entrevista concedida em 29 de maio de 2017). Revista PerCursos,. Florianópolis, v. 18, n. 37, p. 182-193, maio/ago. 2017. Entrevistadores: Lucilene Lisboa de Liz, Dalva Maria Alves Godoy e Marco Antonio Martins. 

possibilidades metodológicas para a educação básica

SOARES, M. Português na escola: história de uma disciplina curricular. In: BAGNO, M. (org.). Linguística da norma. São Paulo: Edições Loyola, 2004. p. 155-178.

SOARES, E. C.; RIBEIRO, P. N. O status dos clíticos no português brasileiro: análise de algumas de suas propriedades em HPSG. ReVEL, [s. l.], edição especial, n. 5, 2011.

TARALLO, F. A. Diagnosticando uma gramática brasileira: o português d'aquém e d'além mar no final do século XIX. In: ROBERTS, I.; KATO, M. A. (org.). Português Brasileiro: uma viagem diacrônica. 2. ed. Campinas: Editora da UNICAMP, 1996. p. 69-105.

VIEIRA, S. R. Colocação pronominal. In: VIEIRA, S. R.; BRANDÃO, S. F. (org.). Ensino de gramática: descrição e uso. São Paulo: Contexto, 2008. p. 121-146.

(Footnotes)

1 Norma Urbana Culta.

2 Esta construção é legítima em algumas variedades do português falado do Brasil, conforme Barros (2011). 